\title{
Maternal and pediatric health and disease: integrating biopsychosocial models and epigenetics
}

\author{
Lewis P. Rubin'
}

The concepts of allostasis (stability through adaptation) and accumulated life stress (McEwen's allostatic load) aim to understand childhood and adult outcomes. Chronic malnutrition, changes in social condition, and adverse early-life experiences may program phenotypes and contribute to long-lasting disease risk. However, integration of life course approaches, social and economic contexts, and comparison among different biopsychosocial models has not generally been explored. This review critically examines the literature and evaluates recent insights into how environmental stress can alter lifelong hypothalamic-pituitary-adrenal axis and immune system responsiveness and induce metabolic and neurodevelopmental maladaptation. Models of biopsychosocial stress overlap but may consider different conditions. Concepts include allostasis, which incorporates hormonal responses to predictable environmental changes, and Geronimus's "weathering," which aims to explain how socially structured, repeated stress can accumulate and increase disease vulnerability. Weathering emphasizes roles of internalized/interpersonal racism in outcomes disparities. For Mexican immigrants and Mexican Americans, the "acculturation" framework has proven especially useful to explore disparities, including preterm birth and neuropsychiatric risks in childhood. Complexities of stress assessments and recent research into epigenetic mechanisms mediating effects of physical, nutritional, psychological, and social stress are reviewed.

A dverse social and psychosocial circumstances, including exposure to social, economic, and psychological stressors, are associated with a variety of poor health outcomes in different parts of the world and in a range of ethnic and age groups $(1,2)$. During the past two decades, epidemiological evidence that early-life stressors increase susceptibility to disease later in life has become supported by a wealth of prospective clinical data, experimental animal models, and an emerging appreciation of the underlying molecular and developmental mechanisms in humans. This emerging paradigm is known as the Developmental Origins of Health and Disease (3). Early-life psychosocial stress has an indirect lasting impact on physiological wear-and-tear via health behaviors, adiposity, and socioeconomic factors in adulthood $(4,5)$. Psychosocial stress may also lead to preterm birth by altering immune system function either independently or in interaction with the neuroendocrine dysfunction (6).

The association between birth weight and the development of traditionally adult-onset diseases, such as type 2 diabetes mellitus and cardiovascular disease, was first demonstrated $25 \mathrm{y}$ ago by Hales et al. (7). In subsequent decades, the hypothesis that environmental factors act on the genome to create differences in vulnerability or resilience has become a central concept in health research, especially maternal child health $(8,9)$. One underlying biological mechanism for effects of fetal deprivation and stress is environmentally inducible epigenetic change (10).

Correspondingly, research on biological mechanisms of health and disease increasingly emphasizes the environmental developmental context. A "critical period" refers to a time window when developmental changes in the organism towards increasing complexity, greater plasticity, and more efficient functioning occur rapidly and may be most easily modified either in favorable or unfavorable directions. Also known as "biological programming," these critical, environmentally sensitive periods underlie the developmental origins of later childhood and adult disease. The critical developmental period model also embraces the possibility that effects of a developmental exposure may be dramatically changed by later physiological or psychological stressors. This expansion of critical period (fetal) effects with later-life effect modifiers provides a plausible framework to approach the interactions between early- and later-life risk factors (11).

A related concept, the "thrifty phenotype," implies that the "thrifty" aspects of adaptation to an early-life nutrient-limited environment can induce later unhealthy permanent changes. A key tenet of the developmental/fetal origins paradigm is fetal undernutrition in mid- to late gestation, which impairs fetal growth, can program later-life poor health including impaired growth, metabolic stress, aberrant glucose tolerance, type 2 diabetes mellitus (7), and cardiovascular disease (12). Experimental evidence stems from the 1960s, when Widdowson and McCance (13) demonstrated that brief periods of undernutrition during critical developmental times are not necessarily followed by "catch-up growth."

Allostasis, which incorporates hormonal responses to predictable environmental changes, can provide an 


\section{Review $\mid$ Rubin}

integrative framework for understanding biopsychosocial stress. Additionally, Geronimus's concept of "weathering" (14) aims to explain how socially structured, repeated stress can accumulate and increase disease vulnerability. Weathering emphasizes the importance of internalized/interpersonal racism as a driver of racial outcomes disparities for African Americans. Similarly, for Mexican immigrants and Mexican Americans, "acculturation" can be an informative and predictive framework to explore disparities, including preterm birth and neuropsychiatric risk in childhood. Although traditional disciplinary investigations have focused separately on how social and physical environmental factors affect children's health, evolving research underscores the importance of integrating approaches (14). Socioeconomic and physical/ chemical environmental dimensions interact, stress being a permissive factor for susceptibility to certain immunologic and toxic insults (15). In addition, unhealthy residential environments and psychosocial stress can co-vary (16), potentiating adverse effects on health and development.

\section{SOCIOECONOMIC STRESSORS AND INFANT AND CHILD HEALTH}

The American psychologist James Garbarino coined the term "socially toxic environments" to describe conditions of poverty and violence (17). Despite improvements in maternal healthcare, socioeconomic differences in birth outcomes remain pervasive, show substantial variation by racial or ethnic subgroup, and are associated with adverse health behaviors that are themselves socially patterned (18). Overall, there is a stepwise gradient in health according to socioeconomic status (SES); that is, people in each class commonly have poorer health outcomes than those just above them and have better outcomes than those below $(19,20)$. The shape of this relationship between SES and health actually may be curvilinear, decreasing health outcomes becoming more common at even higher SES levels (21).

Relative deprivation may be a core mechanism for how income impacts health in societies, i.e., many problems associated with relative deprivation are more prevalent in more unequal societies $(22,23)$. Specific deleterious health outcomes include preterm birth, low birth weight (LBW) $(24,25)$, and child mortality (26). For international disparities in economics, social science, and policy, a commonly utilized measure of statistical dispersion representing the income distribution of a country's population is the Gini Index (27), developed by the statistician and sociologist Corrado Gini in 1912. Modifications of the Gini Index (25) are beginning to be utilized as an indicator of income/wealth inequality in health research. For a century, socioeconomic deprivation in Europe $(28,29)$ and South Asia $(30)$ has been linked to fetal growth. Conversely, improved socioeconomic conditions and nutrition have been associated with increasing birth weight, as occurred in post-World War II Japan. Observations of extreme deprivation during World War II and longitudinal analysis of these historical cohorts have profoundly informed the development of developmental origins theory in the later 20th century. During the Dutch Hunger Winter of 1943-44, the average birth weight declined $200 \mathrm{~g}$ (31) and during the Nazi siege of Leningrad by $500 \mathrm{~g}$ (32).

A second, not mutually exclusive, explanation for effects of scarcity and poverty on health outcomes is psychosocial (or neurobiological) stress. The economic tie is deep-seated social problems, associated with poverty, relative deprivation, or low social status, appear to be more common in more stratified societies (22). Income inequality theory emphasizes that relative deprivation and social stratification, more than direct effects of deprivation of physical living conditions, are a causal link with poor health outcomes (33). In a test of this principle, associations between longitudinal neighborhood poverty trajectories and preterm birth were compared among neighborhoods with long-term low poverty, those with long-term high poverty, and those that experienced increasing poverty early in the study period (34); the latter two neighborhood types had 41 and $37 \%$ increased odds of preterm birth (34). The finding that high (compared with low) cross-sectional neighborhood poverty was not associated with preterm birth (35) supports a relative deprivation thesis.

\section{ALLOSTASIS AND ALLOSTATIC LOAD}

Adaptation to stress comes at a price. The benefits of adaptation (allostasis) and the costs of adaptation (allostatic load (AL)) lead to different trade-offs in health and disease, reinforcing a Darwinian concept of stress. Developmental plasticity has evolved to match an organism to its early environment. But a mismatch between phenotypic outcomes of adaptive plasticity and environmental conditions later in life increases the risk of metabolic and cardiovascular disease.

The concept of allostasis (stability through adaptation) and accumulated life stress, McEwen's AL (36), offers a versatile paradigm to understand childhood and adult health outcomes. The AL essentially is a composite indicator of accumulated stress-induced biological risk whereby chronic or recurrent stress leads to cascading, potentially irreversible changes in biological stress-regulatory systems. Over time, effects of early-life stressors may lead to individual differences in cumulative effects of stress and in stress-related physical and psychological disorders. AL informs several overlapping conceptual biopsychosocial frameworks including weathering (14), acculturation, cumulative physiological dysregulation, and the biological risk profile (37).

Chronic stress exposure can lead to increased AL (36) and premature aging. For example, early-life stress alters brain structure and neuronal connectivity (38). McEwen and Seeman (36) have argued that the AL can be quantified by cataloging specific biomarkers including physiological signs across major biological regulatory systems. This quantification of AL has proved its explanatory power in understanding the relationship between specific stressors and physical health, initially using data from the MacArthur Studies of Successful Aging (39) and National Health and Nutrition Examination Survey (NHANES) data for adults (14). More recently, AL has been employed to predict risk of adverse reproductive (40) and pediatric health outcomes (5), although empiric evidence on 
its utility in pregnancy is conflicting $(35,41)$. Incorporation of a profile of biomarkers for stress, aging, and immune response may permit a more comprehensive and predictive $\mathrm{AL}$ assessment.

\section{WEATHERING}

In the United States, epidemiologic research in the 1990s began to devote attention to the relationships obtaining among racism, social class, and health $(42,43)$. Especially in terms of the American black experience of race, Geronimus's concept of "weathering" was devised to explain how socially structured, repeated stress can accumulate and increase disease vulnerability. Weathering is founded in cumulative disadvantage theory as a framework to explain physical consequences of social inequality. Indeed, chronic stressors are recognized to be particularly salient for poor and minority women, who also experience the highest rates of adverse birth outcomes (44). In the United States, although infant mortality has steadily decreased over several decades, significant racial disparities persist, which suggests that factors that drive rates down may be different from the factors that drive them apart (45).

An important emphasis of weathering is internalized/interpersonal racism and cumulative socioeconomic disadvantage to explain racial health disparities, especially the dramatic black/white differences in birth outcomes. This framework facilitates a reorientation of perinatal psychosocial research from measurement of acute stress, e.g., counts of life events occurring during pregnancy, to measures of chronic stressors. Increased "wear and tear" on an individual who is subjected to repeated challenge or stress chronically taxes the hypothalamic-pituitary-adrenal (HPA) axis leading ultimately to physical and psychological disease vulnerability.

Although race is very much a social construct (46), several linkages might explain associations between race and subsequent health: latent variable institutionalized racism, which may explain racial differences across SES; periconceptional maternal health and support; interpersonal racism (47); potential correlations between phenotypic race and genotype; and epigenetic gene regulation (48), i.e., genetic predisposition or gene-environment/epigenetic modifying risk. In a series of studies in Chicago, between-neighborhood variation (49) in concentrated poverty and low social support predicted the relationship between LBW and maternal age (50). Racial residential racial and socioeconomic segregation disproportionately places African Americans and the poor in more impoverished neighborhoods where access to supermarkets is more limited (51), called food deserts.

A weathering pattern of age-related birth outcomes is particularly observed for African-American women. Maternal age is an important determinant of birth outcomes, in part, presumably representing the mother's level of biological and psychosocial preparation for childbearing. However, in contrast to the J- or U-shaped relationships that exist between maternal age and LBW rates among non-Hispanic white, MexicanAmerican, and non-US-born black women (52), LBW rates among US-born African-American women are lowest in the teens and rise with increasing age $(53,54)$. A population-based test of the weathering hypothesis conducted in first births in Michigan showed African-American women, on average, and those who reside in low-income areas, in particular, experience worsening health profiles between their teens and young adulthood (53). That profile contributes to an increased threefold and fourfold risk for LBW and very LBW, respectively, with advancing maternal age as well as to the black-white prematurity gap $(48,53)$. Further evidence of weathering is the persistence of a black disadvantage in infant mortality for higher SES individuals, a finding attributable entirely to the much higher incidence of LBW (primarily very LBW) among black infants $(54,55)$. The tenacity of this increased risk for African-American infants, even among wealthier and educated mothers, highlights the current imperfect understanding of the biopsychosocial determinants of preterm birth and current policy barriers on preventing prematurity.

\section{ACCULTURATION AND THE HISPANIC PARADOX}

Consideration of health outcomes in ethnic immigrants presents unique challenges. Immigrant health research has emphasized cultural explanations but, until recently, a "social determinants of health" framework, which emphasizes social and structural explanations, has been less commonly used (56). Moreover, ethnicity is a broad category that may incorporate race, cultural tradition, common population history, religion, language, and, often, a shared genetic heritage $(46,57)$.

A striking observation is that health outcomes for Hispanics/ Latinos in the United States, despite frequent socioeconomic disadvantage, are generally more favorable than other ethnic/racial groups such as African and Native Americans. The epidemiologic paradox in longevity was originally proposed more than $30 \mathrm{y}$ ago by Markides and Eschbach (58) and has since been extended to reproductive health and outcomes as a Hispanic Paradox or healthy immigrant paradox. A "Latina epidemiologic paradox" points to the finding that Hispanic mothers in the United States have a similar or lower risk for delivering an LBW infant than non-Hispanic white mothers. However, longer residence for Mexicans in the United States appears to erase any immigrant advantage. An acculturation context becomes valuable to examine this generally observed intergenerational decline in health. A caveat is more granular health outcomes data for US Hispanics shows substantial heterogeneity among countries of origin and number of generations living in the United States.

The US Hispanic paradox in infant and child outcomes is a relatively new epidemiologic phenomenon. Infant mortality rates for the largely Mexican Southwest US Spanish-surname population were not always similar to, or lower than, those for non-Hispanic whites. In fact, throughout the first half of the 20 th century, they were much higher than those of whites, due primarily to shifts in postneonatal mortality $(59,60)$. A change apparently occurred by 1980 , when demographic data sets showed parity or near-parity between infant mortality rates of Hispanic and non-Hispanic white populations in Texas (59) and California (61). 


\section{Review $\mid$ Rubin}

Acculturation is a transitional process that occurs as immigrant groups are exposed to beliefs, traits, and lifestyles of the mainstream culture (62-64). In the mid-20th century, Warner and Strole (65) described a unidirectional acculturation process as ethnic groups shed presumably inferior culturally based health behaviors. Since then, the nativity composition of the United States has changed substantially, largely as a result of immigration from Latin America and Asia following adoption of the Immigration Act of 1965. At present, foreign-born African, Cuban, Mexican, and Chinese women appear to have significantly lower risks of infant mortality, LBW, and preterm birth (66). Recent immigrants generally have better mental health than natives ("immigration advantage") and Mexican immigrants have lower reported rates of psychopathology than the overall US population. Nevertheless, acculturation is different among Hispanic immigrant groups. For example, this mental health observation for Mexican immigrants is less true for Cubans and not true for Puerto Ricans (67).

In some instances, acculturation to the "core culture" may subject individuals to unfavorable social conditions including societal and financial stressors, i.e., AL (68), and attendant poor outcomes (69-71). Mexican acculturation may also be accompanied by loss of social supports, strong family ties, and group identity. Accordingly, health outcomes for immigrants might be bimodal, that is, a combination of the "healthy immigrant" effect (i.e., newer immigrants are healthier) and the effects of acculturation: the longer Mexican immigrants reside in the United States, the greater their likelihood of losing culture-related health protective features (37). Empiric data are inconsistent whether latent sociocultural advantages conferred on Mexican Americans who live in high-density Mexican-American neighborhoods outweigh the disadvantages conferred by high poverty in many of those neighborhoods $(72,73)$.

Acculturation is particularly applicable for understanding health status and intergenerational effects for Mexican women who have emigrated to the United States or live on the US/Mexico border and their offspring. Indeed, the few studies comparing the effect of acculturation across Hispanic subgroups suggest that the experience of acculturation and its effects on health may be different for Mexicans compared with different Caribbean, Central, or South American Latino groups $(63,74,75)$. For Mexican Americans, a graded effect of residence in the United States is seen particularly in pregnancy complications such as excessive gestational weight gain and pediatric morbidities. More generally, Mexican-American women seem to have different health profiles stratified by generation in the United States, which serves as a surrogate measure for acculturation. In particular, LBW increases from first- to third-generation residence (66,76-79).

Although many of these studies demonstrate that immigrant health advantage diminishes over time, rates of LBW in three large datasets instead show a curvilinear effect-first an initial improvement with US residence, then decline-as opposed to the prevailing model of monotonic decline in health measures (80). Over time and US residence/acculturation, prematurity rates (81-84), pregnancy-related hypertension, prenatal depressive symptoms and maternal depression in pregnancy (83), and increased neonatal mortality (68) worsen. From a physiological perspective, increased acculturation has been associated with blunted maternal cortisol rhythms during pregnancy and increased maternal measures of immunity and inflammation $(85,86)$.

A research challenge is many acculturation measures such as language, generation, or self-reported ethnic identity, serve, at best, as proxies that do not fully capture the experience of acculturation $(59,87)$. Acculturation instruments for children and adolescents need more sensitive items to discriminate linguistic differences or measure other factors. Along these lines, the Hispanic Community Health Study/Study of Latino Youth is a multisite epidemiologic study of obesity and cardiometabolic risk among US Hispanic/Latino children. The SOL Youth Study incorporates a parent/child socioecological framework, social cognitive theory, family systems theory, and acculturation research to refine a predictive conceptual model for Hispanic children and adolescent health outcomes (88). From a perspective of mechanism, the extent to which intergenerational differences in reproductive and childhood outcomes are attributable to the intrauterine environment and fetal programming remains poorly understood (89).

\section{A LIFE COURSE APPROACH AND THE DEVELOPMENTAL ORIGINS OF HEALTH AND DISEASE}

Longitudinal models of health disparities have developed (i) from the programming perspective, in which early-life (including fetal) exposures influence health over the lifespan, and (ii) emphasis on cumulative pathways that conceptualize health decline as a result of cumulative wear-and-tear to allostatic systems. Both perspectives build on a stress paradigm and both are synthesized in a "life course" perspective (87) or "life history theory." In reality, disparities in birth outcomes are consequences of differential developmental trajectories set forth by early-life experiences and cumulative AL over the life course (58). Life course epidemiology, therefore, is concerned with risk from biopsychosocial and physical exposures throughout the lifespan $(11,90)$ that influence health and disease independently, cumulatively, and interactively.

The catalyst for a life course approach applied to health research stemmed from a revival of interest in the long-term role of early-life factors. These foundational ecological and historical cohort studies led to the "fetal origins hypothesis" refashioned as the Developmental Origins of Health and Disease (DOHaD) associated with David Barker (91,92), Peter Gluckman (3), and others. The original work examined fetal antecedents of cardiovascular disease in England (93) and has been followed by comprehensive cohort studies from other localities.

The DOHaD hypothesis, which has become a scientific paradigm, states that environmental exposures such as undernutrition during critical periods may have long-term effects on chronic disease risk by "programming" organs, tissues, or body system structure or function. The idea of "biological programming" emerged as an alternative, complementary concept to the adult lifestyle approach to adult chronic disease 
that focuses on how adult behaviors (notably smoking, diet, exercise, alcohol consumption) affect the onset and progression of diseases.

In addition, some long-term consequences of fetal programming show differences in response and susceptibility according to the sex of the individual $(94,95)$. Sex hormones and sexually dimorphic effects of excess glucocorticoid exposure are potential mediators of sex-specific programming of cardiovascular disease $(95,96)$ and depression (96). Proposed mechanisms include sexually dimorphic regulation of blood pressure, vascular remodeling, the fetal HPA and renin-angiotensin systems, and epigenetic marks.

Poor childhood health has been associated with more than threefold greater odds of having poor adult (self-rated) health and twice the risk of a work-limiting disability or a chronic health condition; these associations are independent of childhood and current socioeconomic position or health-related risk behaviors $(97,98)$. Of particular importance in child health, unfavorable birth outcomes and psychosocial deprivation early in life have been associated with adverse health and developmental outcomes and changes in brain architecture $(99,100)$. Moreover, maternal psychological stress or depression during pregnancy, which more often occurs in individuals with low SES, can have profound adverse effects across generations. Biological mechanisms include, "diurnal cortisol coupling," i.e., maternal cortisol dysregulation programs cortisol dysregulation in the offspring $(101,102)$. The findings that fetal and maternal programming occur in parallel has important implications for understanding long-term child development and mother/child interactions (102).

\section{RESILIENCE}

The capacity of brain and body to withstand challenges to stability (homeostasis) is "resilience." Positive early social experience might have a mitigating effect on stress responses later in life via epigenetic mechanisms, which implies a protective role for positive early parental care $(103,104)$. Recent followup from the Bucharest Early Intervention Project asked if randomized placement into a family caregiving environment alters development of the autonomic nervous system and HPA axis in children who were exposed to early-life deprivation and institutional rearing; the results show a causal link between an early caregiving environment and stress response system reactivity in these children $(90,105)$. In this and other studies, although prenatal and early postnatal development is a period of enhanced sensitivity to environmentally inducible deprivation, plasticity beyond human infancy into adolescence and adulthood neurobiological resilience appears possible. Under the right circumstances, the brain can reenter plastic states, and negative outcomes may be mitigated, even later in life (106).

\section{EPIGENETIC REGULATION OF EFFECTS OF PSYCHOSOCIAL STRESS}

Epigenetics studies changes in gene expression that occur without changes in DNA sequence. The term "epigenetics" was first used by Conrad Waddington in 1940 to define the "interaction of genes with their environment which brings the phenotype into being" (107). In effect, the functional history of a gene in one generation can influence its expression in the next. Inherited epigenetic changes in the structure of chromatin can influence neo-Darwinian evolution as well as cause a type of "Lamarckian" inheritance (108).

Epigenetic change is developmental and environmental. Mechanisms underlying the developmental origins of disease and psychosocial models of disease risk involve environmental epigenetics. The developing HPA stress axis is exquisitely sensitive to regulation by social forces represented at the level of the epigenome (20). Specifically, DNA methylation marks have been postulated to be a mechanism for the enduring effects of the prenatal environment. In essence, a newborn's methylome contains a molecular memory of the in utero experience. Epigenetic modifications include DNA methylation (to date, the most extensively studied), covalent modifications of histone tails, and effects mediated by noncoding RNAs such as microRNAs (miRNAs) and long noncoding RNAs (lncRNAs). DNA methylation functions in regulating chromatin structure and remodeling, $\mathrm{X}$-chromosome inactivation, genomic imprinting, chromosome stability, and gene transcription. Addition of a methyl group to cytosines in the DNA sequence as 5 -methyl-cytosine $(5 \mathrm{MeC})$ represents $2-5 \%$ of all cytosines in mammalian genomes and is found primarily on CpG dinucleotides. $5 \mathrm{MeC}$ may be considered as a fifth (developmentally and environmentally regulated) ribonucleotide. One category of developmental epigenetics is "genomic imprinting," a genetic phenomenon by which certain genes are expressed in a parent-of-origin-specific manner via methylation of the unexpressed allele.

Epigenetic marks may be transmitted across generations, either directly by persisting through meiosis or indirectly through replication in the next generation of the conditions in which the epigenetic change occurred. In one commonly cited example of epigenetic inheritance, Hugh Morgan et al. (109) related inherited variations in coat color, diabetes, and other abnormalities in an inbred line of mice (agouti) to variations in the methylation patterns of an inserted retrotransposon. In this instance, the variations are transmitted through female meiosis. In other cases, epigenetic changes are environmentally induced. An example of how variation in maternal diet during early pregnancy can cause persistent changes in DNA methylation in offspring comes from The Gambia, where Dominguez-Salas et al. (110) examined DNA methylation in blood leukocyte and hair follicle samples collected from children born to mothers either during the rainy (hungry) or the dry (harvest) season. Children born in the rainy season, and hence exposed to higher maternal methyl-donor nutrient intake around the time of conception, showed increased methylation of six metastable alleles (110).

A second epigenetic mechanism, posttranslational modifications of histone tails, includes acetylation, methylation, phosphorylation, and ubiquitination. These modifications variably alter chromatin structure and, thereby, DNA accessibility to 
transcription factors and RNA polymerases. Functional effects depend on the specific amino acid modified and on the specific covalently attached group, e.g., acetylation commonly results in the loosening of chromatin and increased gene transcription, whereas methylated histones tightly bind DNA, restrict access to various enzymes, and reduce transcription.

miRNAs are single-stranded RNAs of $\sim 21-23$ nucleotides transcribed from DNA but not translated into proteins (noncoding RNAs). Their functional role includes gene expression regulation mediated by control of messenger RNA (mRNA) stability or translation. miRNA changes may be sensitive indicators of the effects of acute and chronic environmental exposures (111), perhaps permitting identification of miRNA signatures for specific physical and psychosocial environmental exposures.

\section{HEALTH VULNERABILITIES CAN BE HERITABLE}

In the past decade, heritable environmentally induced epigenetic modifications have been revealed to underlie reversible transgenerational alterations in phenotype. In rats, in utero exposure to hydrocarbons, plastics, and dioxin leads to early-onset puberty and spermatogenic cell apoptosis in three subsequent generations. Examination of the sperm promoter epigenome identifies differentially methylated DNA regions in descendants of exposed animals (112). A provocative study linked maternal experience of trauma and consequent posttraumatic stress disorder symptoms to disrupted behavioral and physiological response (i.e., cortisol levels) in the infants (113).

A transgenerational dataset of African Americans indicates women with early-life impoverishment who achieved upward economic mobility showed a decreased incidence of preterm birth compared with women with lifelong impoverishment (114). However, this effect was not seen in women with upward economic mobility who themselves had been LBW. Although numerous interpretations of these findings are plausible, a possible transgenerational epigenetic effect that could not be overcome with a change in SES may be suggested (114). These lines of investigation advance understanding for transgenerational epigenetic effects of disparate environmental exposures as well as possible explanations for the increased risk of adverse health outcomes in minority individuals who otherwise would be considered low risk.

\section{CONCLUSIONS}

More sophisticated and integrative theoretical frameworks variously integrate critical developmental periods, evolutionary-developmental theory, epigenetics, family and community ecology, maternal AL, resilience resources, and local neighborhood and community level influences $(115,116)$. These comprehensive approaches are also applicable to lowand middle-income countries (117). It is imperative that these theoretic frameworks (based on correlations) be tested empirically in order to help build resilience and "stress inoculation." Too little is yet known how the social buffering of the HPA axis that occurs in supportive environments despite mild everyday stressors promotes health (118-120). As knowledge of epigenetic processes grows, so should the capacity to develop early-life interventions to prevent or mitigate child health disparities. As noted by Darlene Francis (20), understanding how genes are differentially regulated by experience will play a profound role in how we conceptualize health inequalities. This understanding should inform our concepts of the somatization or embodiment of social inequalities. Rather than engaging in nature-vs.-nurture debates concerning race as a genetic or social construct, in this sense, race may be viewed as an epigenomic construct in which genotype and the socially experienced world are perpetually entwined (20).

By highlighting sociocultural and socioeconomic attendants to newborn and childhood risk, AL, weathering, and acculturation models suggest policies and interventions grounded in longitudinal and contextual change. An understanding of economic theory about inequalities similarly informs analysis of maternal and childhood health inequities. Priority areas identified for maternal child health research in order to close these knowledge gaps include: epigenetic mechanisms and their potential mutability, periconception as a critical and sensitive period for environmental exposures, maternal health prior to pregnancy, the role of the placenta as an important regulator of the intrauterine environment, and ways to strengthen early mother-child interactions (90). Identification of environmentally modifiable epigenetic marks, such as gene-specific and global DNA methylation, is proceeding at a fast pace. These endeavors will advance sorting out causal relationships between loci-specific programmed epigenetic alterations in response to adverse early environments and metabolic, cardiovascular, and neurodevelopmental disease phenotypes later in life.

\section{REFERENCES}

1. Kim D, Saada A. The social determinants of infant mortality and birth outcomes in Western developed nations: a cross-country systematic review. Int J Environ Res Public Health 2013;10:2296-335.

2. Aizer A, Currie J. The intergenerational transmission of inequality: maternal disadvantage and health at birth. Science 2014;344:856-61.

3. Gluckman P, Hanson M. Developmental Origins of Health and Disease. New York: Cambridge University Press, 2006.

4. Drury SS, Mabile E, Brett ZH, et al. The association of telomere length with family violence and disruption. Pediatrics 2014;134:e128-37.

5. Barboza Solís C, Kelly-Irving M, Fantin R, et al. Adverse childhood experiences and physiological wear-and-tear in midlife: findings from the 1958 British birth cohort. Proc Natl Acad Sci USA 2015;112:E738-46.

6. Segerstrom SC, Miller GE. Psychological stress and the human immune system: a meta-analytic study of 30 years of inquiry. Psychol Bull 2004;130:601-30.

7. Hales CN, Barker DJ, Clark PM, et al. Fetal and infant growth and impaired glucose tolerance at age 64. BMJ 1991;303:1019-22.

8. Godfrey KM, Lillycrop KA, Burdge GC, Gluckman PD, Hanson MA. Epigenetic mechanisms and the mismatch concept of the developmental origins of health and disease. Pediatr Res 2007;61(5 Pt 2):5R-10.

9. Kundakovic M, Champagne FA. Early-life experience, epigenetics, and the developing brain. Neuropsychopharmacology 2015;40:141-53.

10. Heijmans BT, Tobi EW, Stein AD, et al. Persistent epigenetic differences associated with prenatal exposure to famine in humans. Proc Natl Acad Sci USA 2008;105:17046-9.

11. Ben-Shlomo Y. Rising to the challenges and opportunities of life course epidemiology. Int J Epidemiol 2007;36:481-3. 
12. Paneth N, Susser M. Early origin of coronary heart disease (the "Barker hypothesis"). BMJ 1995;310:411-2.

13. Widdowson EM, McCance RA. The effect of finite periods of undernutrition at different ages on the composition and subsequent development of the rat. Proc Roy Soc London B 1963;158:329-42.

14. Geronimus AT, Hicken M, Keene D, Bound J. "Weathering" and age patterns of allostatic load scores among blacks and whites in the United States. Am J Public Health 2006;96:826-33.

15. Wright RJ. Moving towards making social toxins mainstream in children's environmental health. Curr Opin Pediatr 2009;21:222-9.

16. Brody GH, Lei MK, Chen E, Miller GE. Neighborhood poverty and allostatic load in African American youth. Pediatrics 2014;134:e1362-8.

17. Garbarino J. Raising Children in a Socially Toxic Environment. San Francisco, CA: Jossey-Bass, 1995.

18. Blumenshine P, Egerter S, Barclay CJ, Cubbin C, Braveman PA. Socioeconomic disparities in adverse birth outcomes: a systematic review. Am J Prev Med 2010;39:263-72.

19. Braveman P, Barclay C. Health disparities beginning in childhood: a lifecourse perspective. Pediatrics 2009;124:Suppl 3:S163-75.

20. Francis DD. Conceptualizing child health disparities: a role for developmental neurogenomics. Pediatrics 2009;124:Suppl 3:S196-202.

21. Finch BK. Early origins of the gradient: the relationship between socioeconomic status and infant mortality in the United States. Demography 2003;40:675-99.

22. Wilkinson RG, Pickett KE. The problems of relative deprivation: why some societies do better than others. Soc Sci Med 2007;65:1965-78.

23. Adjaye-Gbewonyo K, Kawachi I. Use of the Yitzhaki Index as a test of relative deprivation for health outcomes: a review of recent literature. Soc Sci Med 2012;75:129-37.

24. Huynh M, Parker JD, Harper S, Pamuk E, Schoendorf KC. Contextual effect of income inequality on birth outcomes. Int J Epidemiol 2005;34: $888-95$.

25. Butler RJ, Wilson BL, Johnson WG. A modified measure of health care disparities applied to birth weight disparities and subsequent mortality. Health Econ 2012;21:113-26.

26. Torre R, Myrskylä M. Income inequality and population health: an analysis of panel data for 21 developed countries, 1975-2006. Popul Stud (Camb) 2014;68:1-13.

27. Gini, C. On the Measure of Concentration With Especial Reference to Income and Statistics. Cowles Commission, 1936.

28. Peller S. Das intrauterine Wachstum und soziale. Einflüsse Ztschr $\mathrm{f}$ Konstitutionslehre. 1924;10:307-20.

29. Baird D. The epidemiology of prematurity. J Pediatr 1964;65:909-24.

30. Venkatachalam PS. Maternal nutritional status and its effect on the newborn. Bull World Health Organ 1962;26:193-201.

31. Smith CA. Effects of maternal malnutrition upon the newborn infant in Holland (1944-1945). J Pediatr 1947;30:229-43.

32. Antonov AN. Children born during the siege of Leningrad in 1942. J Pediatr 1947;30:250-9.

33. Popham F. Deprivation is a relative concept? Absolutely! J Epidemiol Community Health 2015;69:199-200.

34. Margerison-Zilko C, Cubbin C, Jun J, Marchi K, Fingar K, Braveman P. Beyond the cross-sectional: neighborhood poverty histories and preterm birth. Am J Public Health 2015;105:1174-80.

35. Morrison S, Shenassa ED, Mendola P, Wu T, Schoendorf K. Allostatic load may not be associated with chronic stress in pregnant women, NHANES 1999-2006. Ann Epidemiol 2013;23:294-7.

36. McEwen BS, Seeman T. Protective and damaging effects of mediators of stress - elaborating and testing the concepts of allostasis and allostatic load. Socioeconomic Status and Health in Industrial Nations. New York: New York Academic Sciences, 1999: 30-47.

37. Crimmins EM, Kim JK, Alley DE, Karlamangla A, Seeman T. Hispanic paradox in biological risk profiles. Am J Public Health 2007;97:1305-10.

38. Philip NS, Valentine TR, Sweet LH, Tyrka AR, Price LH, Carpenter LL. Early life stress impacts dorsolateral prefrontal cortex functional connectivity in healthy adults: informing future studies of antidepressant treatments. J Psychiatr Res 2014;52:63-9.
39. Seeman TE, Singer BH, Rowe JW, Horwitz RI, McEwen BS. Price of adaptation-allostatic load and its health consequences. MacArthur studies of successful aging. Arch Intern Med 1997;157:2259-68.

40. Hux VJ, Catov JM, Roberts JM. Allostatic load in women with a history of low birth weight infants: the National Health and Nutrition Examination Survey. J Womens Health (Larchmt) 2014;23:1039-45.

41. Wallace ME, Harville EW. Allostatic load and birth outcomes among white and black women in New Orleans. Matern Child Health J 2013;17:1025-9.

42. Krieger N, Rowley DL, Herman AA, Avery B, Phillips MT. Racism, sexism, and social class: implications for studies of health, disease, and well-being. Am J Prev Med 1993;9:Suppl 6:82-122.

43. Thomson GE, Mitchell F, Williams MB. Examining the Health Disparities Research Plan of the National Institutes of Health: Unfinished Business. Washington, DC: The National Academies Press, 2006.

44. Misra DP, Straughen JK, Slaughter-Acey JC. Allostatic load and health: can perinatal epidemiology lead the way forward? Paediatr Perinat Epidemiol 2013;27:507-8.

45. Wise PH, Pursley DM. Infant mortality as a social mirror. N Engl J Med 1992;326:1558-60.

46. Burchard EG, Ziv E, Coyle N, et al. The importance of race and ethnic background in biomedical research and clinical practice. N Engl J Med 2003;348:1170-5.

47. Collins JW Jr, David RJ, Handler A, Wall S, Andes S. Very low birthweight in African American infants: the role of maternal exposure to interpersonal racial discrimination. Am J Public Health 2004;94:2132-8.

48. Kramer MR, Hogue CR. What causes racial disparities in very preterm birth? A biosocial perspective. Epidemiol Rev 2009;31:84-98.

49. Morenoff JD. Neighborhood mechanisms and the spatial dynamics of birth weight. AJS 2003;108:976-1017.

50. Cerdá M, Buka SL, Rich-Edwards JW. Neighborhood influences on the association between maternal age and birthweight: a multilevel investigation of age-related disparities in health. Soc Sci Med 2008;66:2048-60.

51. Zenk SN, Schulz AJ, Israel BA, James SA, Bao S, Wilson ML. Neighborhood racial composition, neighborhood poverty, and the spatial accessibility of supermarkets in metropolitan Detroit. Am J Public Health 2005;95:660-7.

52. Deal SB, Bennett AC, Rankin KM, Collins JW. The relation of age to low birth weight rates among foreign-born black mothers: a population-based exploratory study. Ethn Dis 2014;24:413-7.

53. Geronimus AT. Black/white differences in the relationship of maternal age to birthweight: a population-based test of the weathering hypothesis. Soc Sci Med 1996;42:589-97.

54. Schoendorf KC, Hogue CJ, Kleinman JC, Rowley D. Mortality among infants of black as compared with white college-educated parents. N Engl J Med 1992;326:1522-6.

55. Colen CG, Geronimus AT, Bound J, James SA. Maternal upward socioeconomic mobility and black-white disparities in infant birthweight. Am J Public Health 2006;96:2032-9.

56. Acevedo-Garcia D, Sanchez-Vaznaugh EV, Viruell-Fuentes EA, Almeida J. Integrating social epidemiology into immigrant health research: a crossnational framework. Soc Sci Med 2012;75:2060-8.

57. Owen CM, Goldstein EH, Clayton JA, Segars JH. Racial and ethnic health disparities in reproductive medicine: an evidence-based overview. Semin Reprod Med 2013;31:317-24.

58. Markides KS, Eschbach K. Aging, migration, and mortality: current status of research on the Hispanic paradox. J Gerontol B Psychol Sci Soc Sci 2005;60:Spec No 2:68-75.

59. Forbes D, Frisbie WP. Spanish surname and Anglo infant mortality: differentials over a half-century. Demography 1991;28:639-60.

60. Gutmann MP, Haines MR, Frisbie WP, Blanchard KS. Intra-ethnic diversity in Hispanic child mortality, 1890-1910. Demography 2000;37:467-75.

61. Williams RL, Binkin NJ, Clingman EJ. Pregnancy outcomes among Spanish-surname women in California. Am J Public Health 1986;76:387-91.

62. Cabassa LJ. Measuring acculturation: where we are and where we need to go. Hisp J Beh Sci. 2003;25:127-46.

63. Lara M, Gamboa C, Kahramanian MI, Morales LS, Bautista DE. Acculturation and Latino health in the United States: a review of the literature and its sociopolitical context. Annu Rev Public Health 2005;26:367-97. 
64. Mendoza FS, Festa NK. New American children: supporting the health and well-being of immigrant populations. JAMA Pediatr 2013;167:12-3.

65. Warner WL, Strole L. The Social Systems of American Ethnic Groups. New Haven, CT: Yale University Press, 1945.

66. Singh GK, Yu SM. Adverse pregnancy outcomes: differences between USand foreign-born women in major US racial and ethnic groups. Am J Public Health 1996;86:837-43.

67. de Figueiredo JM. Explaining the 'immigration advantage' and the 'biculturalism paradox': an application of the theory of demoralization. Int J Soc Psychiatry 2014;60:175-7.

68. Kaestner R, Pearson JA, Keene D, Geronimus AT. Stress, allostatic load and health of Mexican immigrants. Soc Sci Q 2009;90:1089-111.

69. Himmelgreen DA, Pérez-Escamilla R, Martinez D, et al. The longer you stay, the bigger you get: length of time and language use in the U.S. are associated with obesity in Puerto Rican women. Am J Phys Anthropol 2004;125:90-6.

70. Abraído-Lanza AF, Chao MT, Flórez KR. Do healthy behaviors decline with greater acculturation? Implications for the Latino mortality paradox. Soc Sci Med 2005;61:1243-55.

71. Carter-Pokras O, Zambrana RE, Yankelvich G, Estrada M, CastilloSalgado C, Ortega AN. Health status of Mexican-origin persons: do proxy measures of acculturation advance our understanding of health disparities? J Immigr Minor Health 2008;10:475-88.

72. Osypuk TL, Bates LM, Acevedo-Garcia D. Another Mexican birthweight paradox? The role of residential enclaves and neighborhood poverty in the birthweight of Mexican-origin infants. Soc Sci Med 2010;70:550-60.

73. DeCamp LR, Choi H, Fuentes-Afflick E, Sastry N. Immigrant Latino neighborhoods and mortality among infants born to Mexican-origin Latina women. Matern Child Health J 2015;19:1354-63.

74. Becerra JE, Hogue CJ, Atrash HK, Pérez N. Infant mortality among Hispanics. A portrait of heterogeneity. JAMA 1991;265:217-21.

75. Wojcicki JM, Schwartz N, Jiménez-Cruz A, Bacardi-Gascon M, Heyman MB. Acculturation, dietary practices and risk for childhood obesity in an ethnically heterogeneous population of Latino school children in the San Francisco bay area. J Immigr Minor Health 2012;14:533-9.

76. Cobas JA, Balcazar H, Benin MB, Keith VM, Chong Y. Acculturation and low-birthweight infants among Latino women: a reanalysis of HHANES data with structural equation models. Am J Public Health 1996;86:394-6.

77. Kelaher M, Jessop DJ. Differences in low-birthweight among documented and undocumented foreign-born and US-born Latinas. Soc Sci Med 2002;55:2171-5.

78. Ruiz RJ, Dolbier CL, Fleschler R. The relationships among acculturation, biobehavioral risk, stress, corticotropin-releasing hormone, and poor birth outcomes in Hispanic women. Ethn Dis 2006;16:926-32.

79. Hoggatt KJ, Flores M, Solorio R, Wilhelm M, Ritz B. The "Latina epidemiologic paradox" revisited: the role of birthplace and acculturation in predicting infant low birth weight for Latinas in Los Angeles, CA. J Immigr Minor Health 2012;14:875-84.

80. Teitler JO, Hutto N, Reichman NE. Birthweight of children of immigrants by maternal duration of residence in the United States. Soc Sci Med 2012;75:459-68.

81. Cervantes A, Keith L, Wyshak G. Adverse birth outcomes among nativeborn and immigrant women: replicating national evidence regarding Mexicans at the local level. Matern Child Health J 1999;3:99-109.

82. Crump C, Lipsky S, Mueller BA. Adverse birth outcomes among MexicanAmericans: are US-born women at greater risk than Mexico-born women? Ethn Health 1999;4:29-34.

83. Ruiz RJ, Saade GR, Brown CE, et al. The effect of acculturation on progesterone/estriol ratios and preterm birth in Hispanics. Obstet Gynecol 2008;111(2 Pt 1):309-16.

84. Ruiz RJ, Marti CN, Pickler R, Murphey C, Wommack J, Brown CE. Acculturation, depressive symptoms, estriol, progesterone, and preterm birth in Hispanic women. Arch Womens Ment Health 2012;15:57-67.

85. Ruiz RJ, Stowe RP, Goluszko E, Clark MC, Tan A. The relationships among acculturation, body mass index, depression, and interleukin 1-receptor antagonist in Hispanic pregnant women. Ethn Dis 2007;17:338-43.
86. Buttenheim AM, Pebley AR, Hsih K, Chung CY, Goldman N. The shape of things to come? Obesity prevalence among foreign-born vs. US-born Mexican youth in California. Soc Sci Med 2013;78:1-8.

87. Chun KM, Balls Organista P, Marín G, eds. Acculturation: Advances in Theory, Measurement and Applied Research. Washington, DC: American Psychological Association, 2003.

88. Ayala GX, Carnethon M, Arredondo E, et al. Theoretical foundations of the Study of Latino (SOL) Youth: implications for obesity and cardiometabolic risk. Ann Epidemiol 2014;24:36-43.

89. Fox M, Entringer S, Buss C, DeHaene J, Wadhwa PD. Intergenerational transmission of the effects of acculturation on health in Hispanic Americans: a fetal programming perspective. Am J Public Health 2015;105:Suppl 3: S409-23.

90. Russ SA, Larson K, Tullis E, Halfon N. A lifecourse approach to health development: implications for the maternal and child health research agenda. Matern Child Health J 2014;18:497-510.

91. Barker DJP. Fetal and Infant Origins of Adult Disease. London: British Medical Publishing Group, 1992.

92. Barker DJP. Mothers, Babies and Health in Later Life. 2nd edn. Edinburgh, UK: Churchill Livingstone, 1998.

93. Barker DJ, Martyn CN. The maternal and fetal origins of cardiovascular disease. J Epidemiol Community Health 1992;46:8-11.

94. Gabory A, Roseboom TJ, Moore T, Moore LG, Junien C. Placental contribution to the origins of sexual dimorphism in health and diseases: sex chromosomes and epigenetics. Biol Sex Differ 2013;4:5.

95. Tarrade A, Panchenko P, Junien C, Gabory A. Placental contribution to nutritional programming of health and diseases: epigenetics and sexual dimorphism. J Exp Biol 2015;218(Pt 1):50-8.

96. Goldstein JM, Handa RJ, Tobet SA. Disruption of fetal hormonal programming (prenatal stress) implicates shared risk for sex differences in depression and cardiovascular disease. Front Neuroendocrinol 2014;35:140-58.

97. Haas SA. The long-term effects of poor childhood health: an assessment and application of retrospective reports. Demography 2007;44:113-35.

98. Willson AE, Shuey KM, Elder GH Jr. Cumulative advantage processes as mechanisms of inequality in life course health. Am J Sociol 2007;112 :1886-924.

99. McLaughlin KA, Sheridan MA, Tibu F, Fox NA, Zeanah $\mathrm{CH}$, Nelson CA 3rd. Causal effects of the early caregiving environment on development of stress response systems in children. Proc Natl Acad Sci USA 2015;112:5637-42.

100. Keding TJ, Herringa RJ. Abnormal structure of fear circuitry in pediatric post-traumatic stress disorder. Neuropsychopharmacology 2015;40: 537-45.

101. LeMoult J, Chen MC, Foland-Ross LC, Burley HW, Gotlib IH. Concordance of mother-daughter diurnal cortisol production: understanding the intergenerational transmission of risk for depression. Biol Psychol 2015;108:98-104.

102. Sandman CA, Davis EP, Buss C, Glynn LM. Exposure to prenatal psychobiological stress exerts programming influences on the mother and her fetus. Neuroendocrinology 2012;95:7-21.

103. Weaver IC. Epigenetic programming by maternal behavior and pharmacological intervention. Nature versus nurture: let's call the whole thing off. Epigenetics 2007;2:22-8.

104. Laviola G, Hannan AJ, Macrì S, Solinas M, Jaber M. Effects of enriched environment on animal models of neurodegenerative diseases and psychiatric disorders. Neurobiol Dis 2008;31:159-68.

105. Nelson CA 3rd, Zeanah CH, Fox NA, Marshall PJ, Smyke AT, Guthrie D. Cognitive recovery in socially deprived young children: the Bucharest Early Intervention Project. Science 2007;318:1937-40.

106. Karatsoreos IN, Karatoreos IN, McEwen BS. Annual research review: the neurobiology and physiology of resilience and adaptation across the life course. J Child Psychol Psychiatry 2013;54:337-47.

107. Waddington $\mathrm{CH}$. Organisers and Genes. Cambridge, UK: Cambridge University Press, 1940.

108. Jablonka E, Lamb MJ. The inheritance of acquired epigenetic variations. Int J Epidemiol 2015;44:1094-103. 
109. Morgan HD, Sutherland HG, Martin DI, Whitelaw E. Epigenetic inheritance at the agouti locus in the mouse. Nat Genet 1999;23:314-8.

110. Dominguez-Salas P, Moore SE, Baker MS, et al. Maternal nutrition at conception modulates DNA methylation of human metastable epialleles. Nat Commun 2014;5:3746.

111. Vrijens K, Bollati V, Nawrot TS. MicroRNAs as potential signatures of environmental exposure or effect: a systematic review. Environ Health Perspect 2015;123:399-411.

112. Manikkam M, Guerrero-Bosagna C, Tracey R, Haque MM, Skinner MK. Transgenerational actions of environmental compounds on reproductive disease and identification of epigenetic biomarkers of ancestral exposures. PLoS One 2012;7:e31901.

113. Yehuda R, Bierer LM. Transgenerational transmission of cortisol and PTSD risk. Prog Brain Res 2008;167:121-35.

114. Collins JW Jr, Rankin KM, David RJ. African American women's lifetime upward economic mobility and preterm birth: the effect of fetal programming. Am J Public Health 2011;101:714-9.

115. Braveman PA, Egerter SA, Woolf SH, Marks JS. When do we know enough to recommend action on the social determinants of health? Am J Prev Med 2011;40:S58-66.
116. Ramey SL, Schafer P, DeClerque JL, et al.; Community Child Health Network. The Preconception Stress and Resiliency Pathways Model: a multi-level framework on maternal, paternal, and child health disparities derived by community-based participatory research. Matern Child Health J 2015;19:707-19.

117. Premji S. Perinatal distress in women in low- and middle-income countries: allostatic load as a framework to examine the effect of perinatal distress on preterm birth and infant health. Matern Child Health J 2014;18:2393-407.

118. Hostinar CE, Gunnar MR. Future directions in the study of social relationships as regulators of the HPA axis across development. J Clin Child Adolesc Psychol 2013;42:564-75.

119.Badanes LS, Dmitrieva J, Watamura SE. Understanding cortisol reactivity across the day at child care: the potential buffering role of secure attachments to caregivers. Early Child Res Q 2012;27: 156-65.

120. Roque L, Veríssimo M, Fernandes M, Rebelo A. Emotion regulation and attachment: relationships with children's secure base, during different situational and social contexts in naturalistic settings. Infant Behav Dev 2013;36:298-306. 